\begin{tabular}{|l|l|l|l|l|l|l|}
\hline InterteXto & Uberaba & UFTM & $\begin{array}{l}\text { v. 1 } \\
\text { n. } 2\end{array}$ & p. 114-129 & 2008 - jul. / dez. & ISSN 1981-0601 \\
\hline
\end{tabular}

\title{
A ESCRITA COMO ESPACIALIDADE INCENTIVADORA DO DESEJO EM PRESENÇA DE ANITA
}

\author{
WRITTEN AS ENCOURAGING SPATIALITY OF DESIRE IN PRESENÇA DE \\ ANITA
}

\author{
Ana Carolina Sanches Borges ${ }^{1}$
}

\begin{abstract}
Resumo
Para o registro da obra escrita, muitos instrumentos são utilizados como espaço: papel, computador, pano, etc. No romance Presença de Anita (2001), de Mário Donato, um local que cria condições para o surgimento do erotismo é o papel. Eduardo, arquiteto, desde muito jovem delineia seu ideal de mulher sobre uma folha quadriculada e, na medida em que preenche a lâmina com a forma do corpo feminino, o elemento voluptuoso passa a ser destacado. A corporeidade traçada passa a refletir os anseios do personagem, que busca prazer no que está fazendo. $O$ tratamento dado ao espaço lingüístico recebe destaque e como que se erotiza na busca pelo nome perfeito da figura desenhada pelo protagonista. Portanto, o trabalho com a linguagem em Presença de Anita faz com que o erotismo se una ao espaço, criando um ambiente em que a escrita se torna um lugar de desejo, caracterizado pela liberação da pulsão sexual. Nela, Eduardo revela suas incertezas, suas angústias e seus desejos mais ocultos. Em tal espacialidade, os sentimentos das personagens acabam sendo ressaltados, deixando-se recobrir de mistérios e de desejos e erotizando-se por isso.

Palavras-chave: Erotismo; espaço; romance; psicanálise.
\end{abstract}

\begin{abstract}
In the writing, many instruments are used as space: paper, computer, cloth, etc. In the novel Presença de Anita (2001), by Mário Donato, a place that creates conditions for the emergence of eroticism is the paper. Eduardo, architect, since his youth, draw his ideal woman on a grid sheet and, as the shape of the female body appears, the voluptuous element becomes highlighted. The corporality drew reflects the desires of the character, who seeks pleasure in what he is doing. The treatment given to the linguistic space gets highlighted and become erotized. So, working with language in Presença de Anita makes the eroticism one with the space, creating an environment in which the writing becomes a place of hope, characterized by the release of the sexual instinct. In doing so, Eduardo shows his uncertainties, his fears and his most hidden desires. In this spatiality, the feelings of the characters are emphasized and covered with mysteries and desires.
\end{abstract}

Key-words: Eroticism; space; novel; psychoanalysis.

\footnotetext{
${ }^{1}$ Mestranda pela UNESP-Araraquara. karolsanches@yahoo.com.br
} 


\begin{tabular}{|l|l|l|l|l|l|l|}
\hline InterteXto & Uberaba & UFTM & $\begin{array}{l}\text { v. 1 } \\
\text { n. } 2\end{array}$ & p. 114-129 & 2008 - jul. / dez. & ISSN 1981-0601 \\
\hline
\end{tabular}

\section{Introdução}

O presente artigo visa investigar a escrita como espacialidade propiciadora do desejo, ressaltando a importância do espaço erótico na estruturação do romance Presença de Anita (2001). Por não haver nenhum registro de trabalho sobre o tema, faz-se necessário um estudo em que se alie a abordagem temática do erotismo à categoria narrativa do espaço. A partir disso, questionar-se-á até que ponto o ato de redigir influencia o aparecimento do elemento voluptuoso na espacialidade do texto.

Pela leitura dos livros de Donato ${ }^{2}$, percebe-se que Presença de Anita foi o romance que mais utilizou o elemento erótico. O texto, inclusive, difere da literatura produzida por Cassandra Rios e Adelaide Carraro, pois o escritor soube destacar a sexualidade por meio de um trabalho mais estético e sofisticado, enquanto aquelas autoras parecem não apresentar tais características criativas, contentando-se com o que é explícito sem qualquer qualidade muito complexa e arrojada. Além disso, antes mesmo de Nabokov (Lolita, 1955), Donato cria uma obra esteticamente trabalhada que põe, em primeiro plano, questões existenciais angustiantes que foram sempre abordadas de forma velada, como é o caso do prazer na infância e de seus desdobramentos na vida adulta.

\footnotetext{
${ }^{2}$ Mário Donato é natural de Campinas, São Paulo. Nascido no dia 29 de abril de 1915, trabalhou como operário gráfico e funcionário do Departamento dos Correios e Telégrafos de São Paulo antes de se dedicar ao jornalismo. Trabalhou também em O Estado de S. Paulo, na Folha da Manhã, em A Cigarra, A Gazeta, Diário de São Paulo. Abandonou o jornalismo em 1949 para assumir a direção de programação e, mais tarde, a direção artística de uma emissora de rádio. Três anos depois, foi nomeado vice-presidente da Rádio Nacional de São Paulo. Após lançar-se como poeta, com os livros Terra (1938) e As cigarras emigram (1944), Mário Donato alcançou grande sucesso com seu primeiro romance, Presença de Anita (1948). Com seu segundo romance, Madrugada sem Deus (1954), Donato conquistou o Prêmio Câmara Municipal de São Paulo. Publicou em seguida Galatéia e o fantasma (1957), A parábola das quatro cruzes (1959) e Domingo com Cristina (1963). No campo da literatura infantil é vasta sua produção, com títulos como Cinco irmãos bichanos (1942), Sargentinho (1943) e Espertezas de Jabuti (1947). Com Partidas dobradas (1978), foi vencedor do Prêmio Jabuti da Câmara Brasileira do Livro. Ao morrer, em 1992 e em São Paulo, deixou pronto o livro, ainda inédito, O País dos Paulistas, que conta a história do estado de São Paulo de 1555 a 1964.
} 


\begin{tabular}{|l|l|l|l|l|l|l|}
\hline InterteXto & Uberaba & UFTM & $\begin{array}{l}\text { v. 1 } \\
\text { n. } 2\end{array}$ & p. 114-129 & 2008 - jul. / dez. & ISSN 1981-0601 \\
\hline
\end{tabular}

A erotização, tema constante em Presença de Anita, fez com que Mário Donato, no ano de publicação do livro (1948), vivenciasse dias de glória, mas também de muita polêmica. Aclamado pela crítica como inovador, ousado e erótico, o texto provocou a ira da lgreja, que ameaçou excomungar o escritor. Embora seja vencedor do Prêmio Jabuti da Câmara Brasileira do Livro com o romance Partidas dobradas, publicado em 1978, Donato é quase um desconhecido no âmbito literário atual.

O desejo, presente nas relações entre as personagens do romance, acaba por erotizar os espaços graças aos objetos que fazem parte deles. Assim sendo, os lugares passam a ter um papel de destaque na representação da realidade humana, atribuindo-lhe uma imagem e agindo de tal forma sobre ela, que é possível ver a nu os sentidos e a existência das personagens que compõe o lugar. No mundo do romance, a leitura e a descrição do espaço proporcionam ao leitor sensações que o introduzem no enredo da obra; trama essa em que as personagens estão inseridas.

Em Presença de Anita, a espacialidade pode ser considerada um "[...] conjunto de objetos homogêneos (de fenômenos, de estados, de funções, de figuras, de significações alteráveis, etc.), entre os quais existem relações, semelhantes às habituais relações espaciais (a continuidade, a distância, etc.)" (LOTMAN, 1978, p. 360). Ou seja, de forma mais simplificada, ela pode ser encarada como uma referência "[...] tanto aos objetos e suas relações como ao recipiente, isto é, à localização desses mesmos objetos" (BORGES FILHO, 2007, p. 17).

O erotismo pode contaminar o espaço tanto quanto se pode deixar influenciar por ele. Por isso, em uma análise que visa à erotização espacial, o leitor deve observar os objetos presentes naquele determinado território, como eles auxiliam na construção do espaço erótico e como eles atuam no relacionamento dos personagens do romance. Um abajur, por exemplo, não é um simples artigo. Se ele for citado no texto, é preciso diferenciar a maneira em que foi descrito e se isso remeteu a algum sentido voluptuoso ao lugar. Se ele 


\begin{tabular}{|l|l|l|l|l|l|l|}
\hline InterteXto & Uberaba & UFTM & $\begin{array}{l}\text { v. } 1 \\
\text { n. } 2\end{array}$ & p. 114-129 & 2008 - jul. / dez. & ISSN 1981-0601 \\
\hline
\end{tabular}

estiver apagado ou se sua luz estiver fraca, pode ser que ali estejam presentes dois amantes que, para manterem contato, irão se aproximar mais. Nessa gradação, um clima erótico é capaz de surgir entre ambos, estimulando a consumação de um possível ato sexual. A escolha dos itens de um espaço, portanto, não é mero detalhe de uma descrição; é um recurso utilizado pelo narrador para evidenciar idéias diversificadas no texto. No caso do exemplo do abajur, ele foi um meio de manifestar a sensualidade presente entre duas pessoas, mas que apenas foi propiciada por meio da relação do objeto com o ambiente.

A abordagem da categoria narrativa espacial e do eixo temático da eroticidade são concepções essenciais para o presente artigo e ganham destaque pelo acompanhamento da idéia sobre o espaço erótico. Vale fixar que a construção do termo espaço erótico (influência erótica - sexual ou apenas relacionada à satisfação de um prazer - que um objeto ou uma pessoa possam atribuir à espacialidade literária) apenas foi possível graças à junção dos estudos de teóricos que abordaram, de um lado a espacialidade e, de outro, o erotismo. Não se pode esquecer, todavia, a validade e a importância dos termos empregados pela psicanálise. Portanto, conforme a teoria utilizada, unindo a psicanálise, o espaço e o erotismo, surge uma estreita relação entre objetos, percepção sensorial e personagens, o que é de extrema importância para a análise da construção do espaço erótico no romance Presença de Anita.

\section{A escrita como espacialidade incentivadora do desejo}

Para o registro da obra escrita, muitos instrumentos são utilizados como espaço: o papel, o computador, o pano, etc. No romance, mais especificamente, um local que é privado e que cria condições para o firmamento do erotismo é o papel. Eduardo, arquiteto, mantém desde muito jovem o hábito de desenhar a mesma figura feminina em uma folha quadriculada, a qual se encontra sobre uma prancha em seu ateliê. Durante anos, ele delineia o seu ideal de mulher. Na medida em que o protagonista 


\begin{tabular}{|l|l|l|l|l|l|l|}
\hline InterteXto & Uberaba & UFTM & $\begin{array}{l}\text { v. 1 } \\
\text { n. } 2\end{array}$ & p. 114-129 & 2008 - jul. / dez. & ISSN 1981-0601 \\
\hline
\end{tabular}

preenche a lâmina com a forma do corpo feminino, o elemento erótico passa a ser destacado:

Seis meses antes, lápis ocioso, brincando sobre o papel
quadriculado que a prancha mantinha estendido, ele traçara
um dorso de mulher, um "S" suavemente esguio, as hastes
morrendo no esfumaçamento da grafite, quase como uma
clava de sol que se desenrola e canta em surdina. Uma
cabeleira nasceu ali, desnastrando-se volutuosamente em
longas ondas disciplinadas que se espraiavam nas têmporas
imaginárias. "Quase loura", pensou Eduardo. E a borracha,
raspando de leve o papel, criou aqui e ali o mistério do reflexo
da luz numa cabeleira de mulher. O lápis desceu sôfrego e
tracejou o harpejo breve dos rins, inflou a bacia como uma vela
de súbito panda e mergulhou na descida vertiginosa das coxas,
parando abruptamente no ninho atrás dos joelhos. [...]
(DONATO, 2001, p. 23)

Eduardo dá à figura feminina contornos voluptuosos, concretizados nas imagens do dorso, da clava de sol, da cabeleira e das coxas; que se não são próprios da corporeidade humana, ao menos se assemelham às suas curvas. Os vocábulos inflou e volutuosamente permitem que o próprio erotismo do protagonista emane de forma a constituir, plenamente, todos os seus anseios na representação, que é idealizada pelo personagem e exposta ao leitor como uma mulher quase loura. O narrador continua seu relato, mas agora revelando outras características:

[...] Debuxou-lhe o pescoço - a forma clássica duma taça de champanha, e logo brotaram por si mesmos os seios da figura, minúsculos e atrevidos no corte do perfil, e sob eles, impassível e monótono, adelgaçou-se o ventre, retraindo-se até a raiz das coxas. $E$ os traços escorreram livremente para baixo, interrompendo-se nos joelhos apertados como com medo, guardando um tesouro (DONATO, 2001, p. 23).

No papel, os substantivos ventre e joelhos ${ }^{3}$, um mais estreito e o outro mais apertado, respectivamente, parecem proteger um bem precioso na visão do narrador. A técnica de produção do discurso contribui para que o erotismo

\footnotetext{
${ }^{3}$ Os joelhos são bastante citados pelo narrador, revelando outra faceta do fetichismo no romance.
} 


\begin{tabular}{|l|l|l|l|l|l|l|}
\hline InterteXto & Uberaba & UFTM & $\begin{array}{l}\text { v. } 1 \\
\text { n. } 2\end{array}$ & p. 114-129 & 2008 - jul. / dez. & ISSN 1981-0601 \\
\hline
\end{tabular}

seja cada vez maior no espaço. A minuciosa descrição do narrador, inclusive, cria a possibilidade de o erotismo passar da espacialidade do papel para a área do corpo, pois a figura feminina começa a exercer um domínio encantatório sobre Eduardo.

Se nas revistas que visam à exibição do corpo, a mulher é "[...] submissa ao desejo masculino e ao mesmo tempo portadora de uma sexualidade voraz e insana [...]" (LEITE JÚNIOR, 2006, p. 168), aqui não poderia ser diferente. Porém, além do desejo que possui, Eduardo atribui sentimentalidades à figura. $\mathrm{Na}$ realidade, a corporeidade traçada reflete os próprios anseios do personagem, que busca prazer no que está fazendo. "A definição do prazer, antes de tudo do gozo sexual, está intimamente ligada à percepção que o Sujeito tem de si mesmo e de seu corpo. [...]" (MUCHEMBLED, 2007, p. 98). Assim, o protagonista coloca no papel a impressão que tem de si mesmo e, por isso, o corpo feminino se transforma naquilo que ele gostaria de possuir.

Tamanha é a necessidade que Eduardo tem de aproximar a "criação" da sua realidade que, para atingir o seu objetivo, ele tenta dar um nome perfeito à figura. O capricho e a minúcia, no entanto, não estão apenas na escolha de um nome que agrade ao protagonista, mas também na descoberta de uma denominação que seja tão erótica quanto a imagem que ele havia acabado de traçar:

Chamar-se-ia Cíntia, um nome breve e doído, em í, í tônico, quase gritante, de que se exclama a primeira sílaba individualizante. Ou Lídia? Não, Lídia é casto. Ou Lígia... Não o $g$ pesa para o chão como um ventre adiposo. Sílvia, talvez. Mas Sílvia sibila, tem um quê de serpentino. Vilma, então. O / é trêmulo, hesitante, e o $m$ tardo. E Maria? Nela, o pecado é maternidade: o seu ventre abriga um homem, que é o $i$, e que a incorpora e destrói. Sim, seria Cíntia, a exclamação do sim acompanhada da quebreira de amor da sílaba final [...] (DONATO, 2001, p. 24).

Eduardo faz vários percursos até chegar ao nome aspirado, cujas sílabas e sonoridades se aliam à aparência física e moral da sua mulher tão 


\begin{tabular}{|l|l|l|l|l|l|l|}
\hline InterteXto & Uberaba & UFTM & $\begin{array}{l}\text { v. 1 } \\
\text { n. } 2\end{array}$ & p. 114-129 & 2008 - jul. / dez. & ISSN 1981-0601 \\
\hline
\end{tabular}

idealizada. A vogal $i$ não pode ter qualquer som, deve ser pronunciada de forma exclamativa. As consoantes, por outro lado, devem denotar um sentido positivo e, ao mesmo tempo, erótico e, para tanto, o protagonista dá preferência à consoante $c$. O processo de escolha, então, chega a um nome perfeito: Cíntia. Assim sendo, o tratamento dado ao espaço lingüistíco, em Presença de Anita, recebe destaque e como que se erotiza nessa busca pelo nome certo ${ }^{4}$.

Ao se entregar à escrita do desejo, o protagonista abandona seus próprios preconceitos, agindo conforme discursa Barthes: "O prazer do texto é esse momento em que meu corpo vai seguir suas próprias idéias - pois meu corpo não tem as mesmas idéias que eu" (BARTHES, 2006, p. 24). Desse modo, o espaço da folha e o processo de nomeação ganham eroticidade porque neles está agindo a volúpia de Eduardo, com seu inconsciente sendo constituído "[...] na e pela linguagem, o que sublinha o registro simbólico como aquele dominante no psiquismo e fundante do sujeito do desejo" (FRANÇA, 1997, p. 116).

$\mathrm{Na}$ ação do personagem, um "[...] espaço de fruição fica então criado [...]" (BARTHES, 2006, p. 9). Para que o fato possa acontecer no romance, não é o leitor que se faz necessário ao narrador, "[...] é o espaço: a possibilidade de uma dialética do desejo, de uma imprevisão do desfrute [...]" (BARTHES, 2006, p. 9). Portanto, aqui fica comprovada a importância do espaço para a fixação do erotismo em Presença de Anita.

Possivelmente, Eduardo utiliza a folha sobre a prancheta para violar suas interdições mais íntimas, tentando assumir que, mesmo casado, ainda não encontrou a mulher idealizada há tanto tempo. O que se percebe é que,

\footnotetext{
${ }^{4}$ O narrador, em Lolita (1955), faz um trabalho com os nomes semelhante ao de Presença de Anita (1948): "Lolita, luz de minha vida, labareda em minha carne. Minha alma, minha lama. Loli-ta: a ponta da língua descendo em três saltos pelo céu da boca para tropeçar de leve, no terceiro, contra os dentes. Lo. Li. Ta. Pela manha ela era Lô, não mais que Lô, com seu metro e quarenta e sete de altura e calçando uma única meia soquete. Era Lola ao vestir os jeans desbotados. Era Dolly na escola. Era Dolores sobre a linha pontilhada. Mas em meus braços sempre foi Lolita". (NABOKOV, 2003, p. 11).
} 


\begin{tabular}{|l|l|l|l|l|l|l|}
\hline InterteXto & Uberaba & UFTM & $\begin{array}{l}\text { v. 1 } \\
\text { n. } 2\end{array}$ & p. 114-129 & 2008 - jul. / dez. & ISSN 1981-0601 \\
\hline
\end{tabular}

"[...] apesar de tantos signos esparsos, a linguagem está quase inteiramente por nascer onde a transgressão encontrará seu espaço e seu ser iluminado" (FOUCAULT, 2001, p. 32). O papel, espaço criativo, metamorfoseia-se em lugar de transgressão. Nele, o protagonista exerce um contínuo exercício de voyeurismo, o que permite que Eduardo sublime todas as suas limitações.

No processo relatado acima, a espacialidade da lâmina e a escolha do nome ideal se complementam e se erotizam, revelando o desejo pela mulher perfeita. Conforme diz Poulet: o "[...] lugar dá acesso à mulher, mas também a imagem da mulher dá acesso ao lugar. Dessa curiosa interdependência, ao mesmo tempo topológica e antropológica, o melhor exemplo é seguramente o dos nomes [...]" (POULET, 1992, p. 34). Logo, a escolha do nome auxilia na estabilização da sensualidade local: o papel cria Cíntia, dá acesso a ela; e a figura, por sua vez, com suas características voluptuosas, abre possibilidades para o surgimento do espaço erótico.

Conciliando esse trabalho com as significações dos variados nomes existentes em Presença de Anita, torna-se interessante a análise das identidades de Diana, de Cíntia, de Anita e de Lúcia, todas as personagens do romance e que mantêm uma relação com Eduardo, um dos protagonistas. As nomeações parecem se inter-relacionar e se originar de uma mesma palavra: Ártemis. A figura mitológica da divindade "[...] não é fácil de ser apreendida: ela parece escapar e se multiplicar com aspectos diferentes e muitas vezes contraditórios" (BRUNEL, 2000, p. 95). Por esse motivo, vários autores deram várias denominações e significados à deusa.

Homero criou-lhe adjetivos como matadora de cervos e a que lança flechas. Tanto a obra de Donato, quanto a de Homero possuem suas semelhanças e uma delas é o relato da graciosidade do andar feminino. $\mathrm{Na}$ Odisséia, Ulisses compara Nausícaa à divindade: "Deusa, entre os deuses, senhores dos campos do céu, deves ser Ártemis, a filha do grande Zeus: a altura, a beleza e a maneira de andar, é ela". (Odisséia, canto VI, v. 160). Em Presença de Anita, Eduardo observa a cunhada, Diana, encantado com o jeito 


\begin{tabular}{|l|l|l|l|l|l|l|}
\hline InterteXto & Uberaba & UFTM & $\begin{array}{l}\text { v. } 1 \\
\text { n. } 2\end{array}$ & p. 114-129 & 2008 - jul. / dez. & ISSN 1981-0601 \\
\hline
\end{tabular}

de andar da moça: "Não pôde, entretanto, deixar de admirar a elasticidade do seu passo, a desenvoltura do seu porte semifuso" (DONATO, 2001, p. 194).

Calímaco descreve a deusa como uma "jovem graciosa" em seu Hino e, para o poeta, ela representa a guardiã das estradas, dos portos e dos bosques. Em As suplicantes de Ésquilo, Ártemis é associada à Hécate (v. 675), protetora das parturientes. Em Medéia de Eurípides (v. 397), ela é colocada no mesmo plano que Selene, sendo envolvida nas práticas de feitiçaria (sobretudo porque a arte se dava em lugares selvagens). Ainda em Eurípides (Fenicianas, v. 175), por ser relacionada à Hécate, a divindade acaba sendo associada à lua. Como Ártemis é irmã de Apolo, que tende a se tornar o Sol, então ela tenderia a se tornar a noite, a Lua.

Se para os gregos a significação da deusa é tão complexa, os latinos, por sua vez, simplificaram um pouco as coisas. Para eles, Diana é a divindade lunar e, como todo astro, seria protetora dos trabalhos agrícolas, de acordo com o calendário regulamentado pelas fases da lua. O poeta Catulo (poema 34 ) reúne todos os nomes latinos de Ártemis: Latônia, Lucina $^{5}$ e Luna (alusão a Delos, local de nascimento da deusa segundo a tradição grega). Um dos nomes dados por Catulo, Lucina, pode ser associado a uma das personagens do romance: Lúcia. Pelo brilho da lua, Lúcia e Lucina representariam a luminosidade emanada pelo astro. Virgílio, em Eneida (canto IV, v. 511), compreende Diana em três aspectos: terrível e subterrânea como Hécate, terrestre e silvestre como Diana e luminosa como Feba. Portanto,

\footnotetext{
${ }^{5}$ Grifo nosso para destacar a semelhança com o nome Lúcia.
} 


\begin{tabular}{|l|l|l|l|l|l|l|}
\hline InterteXto & Uberaba & UFTM & $\begin{array}{l}\text { v. 1 } \\
\text { n. } 2\end{array}$ & p. 114-129 & 2008 - jul. / dez. & ISSN 1981-0601 \\
\hline
\end{tabular}

[...] Tudo se passa como se num trabalho de síntese e racionalização permitisse construir um perfeito paralelo entre Ártemis e seu irmão Apolo, a quem Homero dava o nome de Phoibus, em latim Phoebus. Assim, Ártemis, tornada Diana, recebe ao lado dos antigos nomes gregos, como Dictynna, nomes que refletem os de Apolo: Cíntia ${ }^{6}$, por exemplo, ou Delia (BRUNEL, 2000, p. 97).

Relacionando os nomes de Cíntia a Ártemis, chega-se, portanto, ao nome Diana. Outro nome que adentra o interessante jogo de significados é o nome da protagonista do romance aqui analisado. Anita, diminutivo de Ana, faz um paralelo com a terminação do nome (Di)Ana. Para o nome da personagem, o narrador dá um sentido parecido ao adjetivo que Homero empresta à deusa Ártemis (a que lança flechas). Em uma passagem, por exemplo, Eduardo tem a impressão que a amante é quase como "[...] o tremor nervoso duma flecha que vibra no arco antes de soltar-se" (DONATO, 2001, p. 32). O fato de o nome da personagem estar no diminutivo é capaz de remeter à idéia de ela ser menos importante para Eduardo, em comparação com a cunhada dele, Diana. Se no início do romance o protagonista se apega à Anita; com a morte desta, ele ganha espaço para perceber o valor da cunhada. Isso ocorre quando o protagonista, ao desenhar sua parenta, surpreende-se por ela se assemelhar ao desenho de Cíntia (mulher idealizada).

A partir do momento em que o protagonista descobre que Cíntia e Diana são a mesma pessoa, as outras mulheres perdem interesse para ele. Curiosamente, se ambas as personagens possuem suas semelhanças, 0 mesmo ocorrerá com os nomes de Anita e de Conchita. O nome da jovem rima com o da boneca, personagem que Eduardo destruirá no final do romance para se ver livre do espectro da amante, pois achava que elas eram a mesma pessoa. Se a jovem possui em seu nome a terminação semelhante ao nome de (Conch)ita, deve-se considerar também o fato de que Anita e Conchita são

\footnotetext{
${ }^{6}$ Grifo nosso.
} 


\begin{tabular}{|l|l|l|l|l|l|l|}
\hline InterteXto & Uberaba & UFTM & $\begin{array}{l}\text { v. 1 } \\
\text { n. } 2\end{array}$ & p. 114-129 & 2008 - jul. / dez. & ISSN 1981-0601 \\
\hline
\end{tabular}

nomes de descendência espanhola ${ }^{7}$. No espaço da escrita do desejo, surge mais um coincidência entre as personagens: a música que parece ser cantada pela boneca:

\author{
El primero tiene "de", \\ el segundo tiene "don", \\ pero el tercero es con \\ quien yo me acostaré! (DONATO, 2001, p. 14)
}

Durante boa parte do romance, a copla "[...] que falava de alguém que desprezava dois admiradores com de e don no nome, para se deitar com o homem que amava" (DONATO, 2001, p. 14), é revisitada, principalmente por Eduardo quando ele rejeita Anita e Lúcia para viver com Diana. Segundo o personagem Dr. Eugênio, a cançoneta era antiga e pertencia a uma "[...] velhota espanhola que a cantava no Moulin Rouge [...]" (DONATO, 2001, p. 288). Cabe ressaltar que o espaço em que a senhora recitava a canção ainda é, até os dias atuais, um lugar de significativo erotismo. A composição, inclusive, pode ser associada à vida do protagonista, pois Eduardo escolhe duas mulheres para se relacionar (esposa e amante), mas é apenas com a terceira que ele decide viver para sempre (a cunhada). Ademais, aos leitores, a canção consegue se fazer familiar se comparada à música infantil Terezinha de Jesus, cujo relato descreve o relacionamento feminino com três homens (sendo o pai considerado o primeiro amor da filha): "Terezinha de Jesus, de uma queda foi ao chão, acudiram três cavalheiros, todos de chapéu na mão. $O$ primeiro foi seu pai, o segundo seu irmão e o terceiro foi aquele a quem Teresa deu a mão".

\footnotetext{
${ }^{7}$ Pierre Louÿs, autor clandestino da França do Fin de Siécle, também criou uma personagem Conchita em La femme et le pantin no ano de 1898. A personagem espanhola, uma moça tão jovem quanto Anita, era uma dançarina de cabaré que tinha o poder de destruir os corações masculinos e que acabou destruindo a vida de um homem mais velho. Um outro dado interessante é o fato de Nabokov ter escolhido para sua protagonista um nome espanhol: Lolita. Seria uma tentativa dos autores de sugerir, por meio dos nomes, toda uma carga semanticamente sensual nas figuras femininas? Se forem pesadas as atitudes de cada personagem, nos respectivos romances e de acordo com seu relacionamento com os homens, essa resposta parece ser afirmativa, ainda que em uma análise superficial.
} 


\begin{tabular}{|l|l|l|l|l|l|l|}
\hline InterteXto & Uberaba & UFTM & $\begin{array}{l}\text { v. 1 } \\
\text { n. } 2\end{array}$ & p. 114-129 & 2008 - jul. / dez. & ISSN 1981-0601 \\
\hline
\end{tabular}

$O$ trabalho com a linguagem em Presença de Anita faz com que o erotismo se una ao espaço, criando um ambiente em que a escrita se torna um lugar de desejo. Portanto, a forma de relação com os nomes, no romance, parece não ser meramente casual. As nomeações, ao estarem interligadas, demonstram uma relação com Ártemis, realçando a polionimia da deusa. Diana se torna um nome-máscara, correspondendo à psique das personagens do romance e atribuindo-Ihes características de forma indireta. Cabe citar a teoria das máscaras de Tomachevski em que o autor afirma que não "[...] só as descrições dos objetos, daquilo que se oferece à vista, mas também qualquer outra descrição pode servir de máscara. O próprio nome do herói é capaz de ter esta função [...]" (TOMACHEVSKI, 1965, p. 170), ou seja, os nomes conseguem designar um traço característico de cada personagem. Portanto, tomando-se por base o significado "caçador" da deusa Ártemis, ter-se-ia Diana, Cíntia e Anita procurando conquistar o amor de Eduardo. Por outro lado, Lúcia, sua esposa, encaixar-se-ia apenas no papel de mãe e esposa zelosa, denotando um sentido de pureza e luminosidade; uma pessoa a quem o prazer foi privado.

O tratamento que Eduardo dá à figura de Cíntia no papel quadriculado, criando um espaço de desejo por meio da escrita, será o mesmo dado aos traços que fará da cunhada, Diana. Certo dia, sozinho com a parenta em um quarto de hotel, resolve desenhá-la. A moça, magoada pela rejeição do protagonista, como "[...] uma leoazinha irritada, media o aposento a largos passos [...] os olhos apertados, sem dizer palavra" (DONATO, 2001, p. 193). Eduardo, indiferente ao comportamento colérico da cunhada, senta-se na poltrona e fica a rir do comportamento da moça, achando-a "[...] não trágica, mas apenas divertida" (DONATO, 2001, p. 194). O protagonista fica a admirar a elasticidade dos passos de Diana, sem que ela se volte para ele. Então, achando graça da situação, o homem se levanta para pegar uma caderneta a fim de riscar os contornos da cunhada: 


\begin{tabular}{|l|l|l|l|l|l|l|}
\hline InterteXto & Uberaba & UFTM & $\begin{array}{l}\text { v. 1 } \\
\text { n. } 2\end{array}$ & p. 114-129 & 2008 - jul. / dez. & ISSN 1981-0601 \\
\hline
\end{tabular}

Rindo, Eduardo levantou-se para tirar do bolso interno do paletó uma caderneta que usava para apontamentos. E, voltando para a poltrona, pôs-se a desenhar a moça, sem olhála, rapidamente, cobrindo e recobrindo os traços, primeiro o dorso não de todo disfarçado pelo enfunado da pelica, as pernas de efebo, o ventre retraído sob a saia apertada, os seios pequeninos contidos pelo corte do costume severo que ela usava, e, no rosto, onde nada mais lhe importava, o narizinho reto, distante da boca, com as narinas aflantes, vibráteis, sensuais. Tudo em volta dela, magnetizado pela sua fúria, Ihe acompanhava o passo e cirandava doidamente, a camiseira se espichando para agarrá-la, os encostos das cadeiras se estorcendo, ela vencendo no esforço o chão em ladeira... (DONATO, 2001, p. 194)

A descrição do seu desenho coincide com os traços da Cíntia de seus sonhos. No espaço da poltrona, ele se sente à vontade para representar com calma e atenção os detalhes do corpo de Diana. Ao esboçar o dorso, o ventre, os seios e a boca, o homem acaba contribuindo para a fixação do erotismo na planície do papel. Conforme projeta a figura da cunhada, Eduardo imagina que os objetos do espaço estão sendo atraídos pela presença magnetizante da moça. A camiseira, os encostos das cadeiras e o chão parecem se inclinar à sensualidade de Diana e, por isso, o ambiente do quarto vai se erotizando, atribuindo, outrossim, voluptuosidade à representação na folha.

Flávia Regina Marquetti possui uma visão interessante sobre o conteúdo sedutor que uma imagem ou uma descrição podem causar no ser humano, mais especificamente no pensamento dos homens. Para ela, não apenas os retratos de "[...] Afrodite nos hinos a ela dedicados, mas também o de Sherazade, de Capitu e tantas outras femmes fatales da literatura, do cinema e da vida [...]" (MARQUETTI, 2003, p. 178) fazem com que a mente masculina solte a imaginação no espaço do papel. Logo, um retrato ou um desenho conseguem se transformar em caminhos poderosos a fim de despertar o prazer diante da visão humana.

Os contornos de Diana trazem para diante dos olhos do protagonista a mulher dos seus sonhos e o resultado Ihe será revelador: "Eduardo teve nesse 


\begin{tabular}{|l|l|l|l|l|l|l|}
\hline InterteXto & Uberaba & UFTM & $\begin{array}{l}\text { v. } 1 \\
\text { n. } 2\end{array}$ & p. 114-129 & 2008 - jul. / dez. & ISSN 1981-0601 \\
\hline
\end{tabular}

instante um deslumbramento. Daquela tosquidão de roupas que a deformavam, emergia para ele, heróica e nua, as formas trementes como no suspenso dum longo e áspero esforço que a libertava, emergia Cíntia" (DONATO, 2001, p. 195). Ao homem é mostrado o que está no mais íntimo do seu ser e o protagonista liberta o ser feminino que tanto desejou. Isso apenas ocorre graças à folha de papel, a qual possibilita que Eduardo sobreponha as figuras de Cíntia e de Diana, surpreendendo-se com o resultado. A técnica se aproxima do trabalho do sonho destacado por Freud, em que o processo central é o deslocamento e a condensação. Para o psicanalista, a construção de figuras coletivas e compostas é um dos principais métodos de atuação da condensação, sendo que uma das formas para que esse processo apareça claramente é o trabalho com palavras e nomes. De acordo com o pensamento freudiano, o protagonista condensa seus recalques, escolhendo, por vias eróticas, o nome e a figura de Cíntia.

Diana, por sua vez, percebe toda a tensão sexual do amado. Numa noite e em um quarto de hotel, a moça pressente a excitação do cunhado a contemplar seu belo corpo feminino. Ela, que anda de um lado a outro no aposento, sente o olhar confiante de Eduardo sobre sua corporeidade, a pousar-Ihe "[...] nas pernas nuas, depiladas, primeiro de leve, eletrizando-a, depois sofregamente, e subir-lhe pelas coxas enrubescidas como um réptil inexorável que fosse fendê-la de alto a baixo" (DONATO, 2001, p. 197). Para marcar a caracterização erótica no corpo da jovem, o narrador utiliza a figura do réptil inexorável para destacar Diana como um espaço de desejo para Eduardo. O olhar masculino caminha para a estrutura física feminina, como um réptil pronto a devorá-la. No entanto:

[...] o réptil não a penetrava, como agora ela queria e para quem entreabria os joelhos finos, na enorme fraqueza que a tomava: coleava-lhe à altura dos rins, enlaçava-se sob os seios e, soerguendo-os, mordiscava-lhes os mamilos, e logo the mergulhava por sobre o ventre, desenrolando-se em longas e intérminas espirais, até sumir-lhe no vértice das coxas e ali, 


\begin{tabular}{|l|l|l|l|l|l|l|}
\hline InterteXto & Uberaba & UFTM & $\begin{array}{l}\text { v. 1 } \\
\text { n. } 2\end{array}$ & p. 114-129 & 2008 - jul. / dez. & ISSN 1981-0601 \\
\hline
\end{tabular}

furioso e lento, pesado e refletido, bater, bater e bater, acordando o desejo e mantendo-o desperto, na sua jaula aprisionado (DONATO, 2001, p. 197).

De maneira similar às imagens sobrepostas das mulheres, a descrição do espaço erótico em Diana é semelhante à figurativização de Cíntia. É por isso que o substantivo réptil se metamorfoseia em uma espécie de "reprodução" do desejo masculino, assegurando a masculinidade de Eduardo e o seu desejo de possuir sexualmente a cunhada. Os verbos penetrava, entreabria e mordiscava complementam o trabalho com a figura do animal, revelando a eroticidade do lugar e do momento. Embora o topos seja o do próprio corpo, é nele que, por meio da visão, o espaço ganha sentido erótico. Diana sente Eduardo cobiçando suas pernas e tomando-as em um ponto de pulsão erótica.

A espacialidade erótica, possibilitada pelo artifício da escrita em Presença de Anita, portanto, caracteriza-se pela liberação da pulsão sexual. Nela, Eduardo encontra segurança e cumplicidade. Ele acaba sendo incentivado a revelar suas incertezas, suas angústias e seus desejos mais ocultos. É um lugar em que surge o aparecimento do desejo (quando ele observa os traços voluptuosos de Diana), do refúgio (sentimento revelado pelo desenho de Cíntia), da entrega total e do conhecimento de si (Eduardo descobrindo que o desenho de Diana, no papel, possui as mesmas características das de Cíntia, a mulher idealizada). Desse modo, o espaço construído pela linguagem e pela escrita acaba incentivando a liberação dos recalques e o aparecimento do erotismo e, nessa espacialidade, os sentimentos das personagens acabam ganhando destaque, deixando-se recobrir de mistérios e de desejos e erotizando-se por isso.

\section{Referências}

BARTHES, Roland. O prazer do texto. São Paulo: Perspectiva, 2006. 


\begin{tabular}{|l|l|l|l|l|l|l|}
\hline InterteXto & Uberaba & UFTM & $\begin{array}{l}\text { v. } 1 \\
\text { n. } 2\end{array}$ & p. 114-129 & 2008 - jul. / dez. & ISSN 1981-0601 \\
\hline
\end{tabular}

BRUNEL, Pierre. Dicionário de mitos literários. Rio de Janeiro: UNB/ J.

Olympio, 2000.

DONATO, Mário. Presença de Anita. Rio de Janeiro: Objetiva, 2001.

BORGES FILHO, Ozíris. Espaço e literatura: introdução à topoanálise. Franca:

Ribeirão Gráfica e Editora, 2007.

FOUCAULT, Michel. Prefácio à transgressão. In MOTA, Manoel Barros (Org.).

Estética: literatura e pintura, música e cinema. Tradução Inês Autran Dourado

Barbosa. Rio de Janeiro: Forense Universitária, 2001.

FRANÇA, Maria Inês. Psicanálise, estética e ética do desejo. Perspectiva, 1997.

LEITE JÚNIOR, Jorge. Das maravilhas e prodígios sexuais: a pornografia "bizarra" como entreterimento. São Paulo: Annablume, 2006.

LINS, Osman. Lima Barreto e o espaço romanesco. São Paulo: Ática, 1976.

LOTMAN, luri. A estrutura do texto artístico. Lisboa: Estampa, 1978.

MARQUETTI, Flávia Regina. Encanto de sereia: a permanência de traços arcaicos de imagens de Vênus. In FEITOSA, Lourdes Conde; FUNARI, Pedro

Paulo A.; SILVA, Glaydson José da. (Org). Amor, desejo e poder na

Antiguidade: relações de gênero e representações do feminino. Campinas:

UNICAMP, 2003. p. 197-216.

MUCHEMBLED, Robert. O orgasmo e o ocidente: uma história do prazer do século XVI a nossos dias. Tradução Monica Stahel; Apresentação Mary del

Priori. São Paulo: Martins Fontes, 2007.

NABOKOV, Vladimir. Lolita. Tradução Jorio Dauster. Rio de Janeiro: O Globo;

São Paulo: Folha de São Paulo, 2003.

POULET, Georges. O espaço proustiano. Tradução Ana Luiza Borralho Martins Costa. Rio de Janeiro: Imago, 1992.

TOMACHEVSKI, Boris. Temática. In BRICK, O. et al (Org). Teoria da literatura

II. Tradução Isabel Pascoal. Rio de Janeiro: Ed. 70, 1965. p. 169-204. 